\title{
The Howie Code: what are the real costs?
}

\author{
CH COLLINS, ${ }^{*}$ JW HOWIE $\dagger$
}

From ${ }^{*}$ The Ashes, Hadlow, Kent and $† 34$ Redford Avenue, Edinburgh

SUMMARY The costs of implementing the Code of Practice for the Prevention of Infection in Clinical Laboratories appear to have been inflated in various ways. These include: alterations and improvements not required by the Code; rehabilitation of neglected buildings to conform with the requirements of the Health and Safety at Work Act; correction of poor design in recently built laboratories; suboptimal management and courses of instruction; and numerous committees.

Since the publication, in late 1978, of the Code of Practice for the Prevention of Infection in Clinical Laboratories and Post-Mortem Rooms, ${ }^{1}$ usually referred to as the Howie Code, there have been many estimates and complaints about the apparent costs of its implementation. Curiously enough, although a draft of the Code had been circulated to many professional (and other) bodies for consultation since the spring of 1977 the flood of objections did not commence until the autumn of 1979. By coincidence, the Health and Safety Executive published, also in 1979, its Discussion Document Dangerous Pathogens: Draft Regulations and Draft Guidance Notes. ${ }^{2}$ If implemented, this would have made it extremely difficult and expensive for clinical laboratories to conduct their business. We cannot help but wonder, in view of the time lag, if this document triggered off many of the objections to the Howie Code. Furthermore, an increasing number of these objections came from individuals and organisations not involved in laboratory work and certainly not at risk.

Some of these complaints and criticisms have already been answere ${ }^{3}$ and at least one ${ }^{4}$ although more recent, seems to have been conditioned by the belief that because the incidence of laboratoryacquired hepatitis has declined, the hazards of other infections-for example, tuberculosis and typhoid fever, may also be discounted. Here, however, we wish to confine our observations and remarks to the allegations that the price of safety is too high. ${ }^{4}$

Although we have never claimed that the costs of implementing the Howie Code would be negligible in every laboratory our continuing, but necessarily private and unofficial investigations into apparently

Accepted for publication 22 August 1983 high costs have convinced us that these expenses fall in to two groups:

(i) Those that are illusory and are the results of the inflation of real costs for administrative reasons-for example, the inclusion of unnecessary expenditure and of alterations and equipment that are not required by the Howie Code. Some Category B laboratories come into this group.

(ii) Those incurred by the neglect of older buildings; poor design of newer premises; suboptimal management that has led to incorrect choice of equipment and poor maintenance; feeble attempts to instruct those at risk in the Good Laboratory Practices required not only to protect their own health but also that of patients and the general public; and by the many committees that have been convened to consider the problems, if any, of safe microbiological procedures.

\section{ILLUSORY AND INFLATIONARY COSTS}

Simple inflation, for whatever reasons and for which the Howie Code should certainly not be billed may be demonstrated by two incidents and one serious doubt.

The cost of fitting four handbasins in a laboratory built in 1970 was over $£ 3000$ (1980 prices). The account submitted by a private builder for fitting handbasins into four bedrooms in a very old house (with early Victorian plumbing) was $£ 456$. A sum of $£ 18000$ was quoted for the provision of a staff rest room, but this concealed the cost of an additional office not required by the Howie Code. A prefabricated extension to existing premises would have cost under $£ 4000$.

It is difficult to believe that some of the very high costs quoted-for example, by Cohen, ${ }^{4}$ for "raising laboratories to Howie standards" do not include many other, probably desirable, features which are 
nevertheless not required by that Code. If they are then they may be the result of failure to keep the premises in good order.

\section{NEGLECT OF OLDER BUILDINGS}

There is no denying the unpleasant fact that it will cost very large sums of money to make some older laboratories habitable if not reasonably safe and convenient places in which to work. Laboratories were excluded from the various Factory Acts and even from the Offices, Shops and Railway Premises Act. There was thus no compulsion to keep them in a state of repair. It is quite improper, however, to attribute to the Howie Code (or to the Health and Safety Executive) the costs of repairing floors and stairways, leaking roofs, unsafe electricity and gas installations, all of which, and more, have been revealed in the course of our enquiries. This is not the price of safety; it is the price of uncaring administration and unequal allocation of funds.

\section{POOR DESIGN OF NEWER LABORATORIES}

One does not need to study the recent Report of the Committee of Public Accounts, ${ }^{5}$ to find evidence that very large sums of money will be involved in putting right errors in design that should never have been accepted. As has been pointed out at length elsewhere $^{6}$ all the information needed to design reasonably safe and convenient laboratories, suitable for the work they are intended to perform has been available for many years, not only from the professional staff of the Department of Health and Social Security (DHSS), but from the many examples of good and bad design that are already in existence and available for study. It would be invidious to name bad examples, but two good ones may be cited, both designed and built before the Working Party which produced the Howie Code was even considered.

The Dulwich (London) Hospital Pathology laboratory was built in 1968. The architect had had previous experience in laboratory design and worked very closely with the staff of the Dulwich and King's College Hospital Pathology Departments. The result was an excellent suite of laboratories, providing comfortable and safe working conditions for the staff. The only alterations necessary to satisfy the Howie Code requirements were the provision of some handbasins and a counter to receive specimens. The expense was minimal (This was not the laboratory referred to above, where the cost of handbasins was exorbitant).

The Dulwich Public Health laboratory was added to the Hospital laboratory in 1972, and was based largely on the design of the latter, with the added experience of the Public Health Laboratory Service
(PHLS). The same architect collaborated with us to produce a laboratory which was completed and occupied within twelve months. It has required neither structural alterations nor any other expense to satisfy the requirements of the Howie Code.

\section{CATEGORY B LABORATORIES}

Much very heavy weather has been made about the requirement for a separate room for work with the more hazardous micro-organisms-for example, tubercle bacilli, where the risks to laboratory workers of infection by the aerosol route has been fully appreciated since the 1950 s. $^{7}$ In fact, most public health and many hospital laboratories already had such rooms as a result of recommendations made since that time. As the Howie requirements are simple and virtually no additional services are required-apart from a microbiological safety cabinet and a hand basin, which should be available anyway-the cost of converting a room should be negligible. It has frequently been inflated, however, to deter possible alterations which might cause inconvenience. Even extensions are not prohibitively expensive and those that are prefabricated by specialist companies may, in fact, be cheaper and better than locally designed and built premises.

Category B rooms are certainly cheaper than the containment rooms specified for the handling of radioisotopes, about the cost of which there has been no outcry.

\section{EQUIPMENT}

In general the budgets of microbiological laboratories are much more modest than those of other pathology departments, where the equipment is more sophisticated and is frequently replaced. Yet serious objections have been raised to the costs of three items required by the Howie Code: microbiological safety cabinets; safety buckets for centrifuges; and containers for the transport of specimens.

Safety cabinets have been in general use in the PHLS since the late 1950s. Any hospital authority that heeded the recommendations of DHSS in 1970 and $1972^{89}$ will already have them installed. Any costs arising from implementing the Howie Code will be for the replacement of old, dilapidated, or unsatisfactory cabinets and the correction of installation faults. All equipment ages and ten years is a reasonable life span for an item costing about $£ 2000$ at today's prices. (One of us has in daily use a PHLS 1970 cabinet, now about 12 years old which, as the result of good maintenance, is still in excellent condition and is fully effective.)

Unfortunately, some cabinets have not been satis- 
factory, either intrinsically or because of incorrect installation.

The cost of new or improved installation depends on several factors. One is the skill of the installer. Cabinet manufacturers usually do a better job, and charge less than organisations that have little or no previous experience. Laboratory design is also important. The costs of providing safety cabinet installations as afterthoughts or in unsuitable parts of a building are likely to be astronomic. Such high costs can be avoided by consultation and by using the expertise residing with the technical officers of DHSS and with the PHLS.

Centrifuges, like safety cabinets, do not last for ever and the need to replace them when they cease to work properly and safely is obvious. The cost of new machines, to replace those deemed unsatisfactory by HSE Inspectors, who have sound industrial experience of these appliances, should not be a charge against the Howie Code. The Code requires only the provision and use of sealed centrifuge buckets, available to fit most centrifuges. These are the only financial charges that can be made in this respect, but even so, authorities that followed the example of the PHLS ${ }^{10}$ will already be using such buckets. In any case, they are not very expensive.

Inexpensive boxes and trays that are eminently suitable for the transport of specimens have been in use in some laboratories-for example, at Dulwich, for many years. It is, perhaps, unfortunate that the Howie Code did not give details. This would have avoided the claims that suitable containers are costly and would ruin a laboratory budget.

\section{COURSES OF INSTRUCTION IN SAFETY}

It is an unfortunate fact of life that many colleges where microbiology is taught do not include very much instruction in the safe handling of pathogenic microbes. There were no courses on microbiological or other aspects of laboratory safety until 1975 when a group of private individuals was able to institute an annual series under the aegis of a local education authority. ${ }^{11}$

Two years after the publication of the Howie Code, and acting presumably on one of the (unpublished) recommendations of the Howie Working Party, official sanction was given for courses to be conducted by regional or area health authorities. Unfortunately some of these courses do not measure up to the standards of those that were held outside the National Health Service (NHS) because too many health authorities incorrectly assumed that all senior laboratory staff knew all about laboratory safety and could teach it to others. There was also much duplication of material and the inclusion of irrelevant subject matter.
Much money was spent on these courses and it seems likely that few of them were "cost-effective". It would appear now, however, that they are at an end but that there is no money left for NHS staff to attend the better organised and more useful external courses. It is worth noting here that courses along the lines recommended by the Howie Working Party-that is, "organised on a national basis, so that the same basic professional instruction is given ... throughout the country" have recently been held in New Zealand through the cooperation of the health and university authorities, the New Zealand Institute of Medical Laboratory Technology, and the New Zealand Microbiological Society. Reports from New Zealand, which has a population of only 3000000 , and where over 400 laboratory workers attended courses in six different cities, suggest that these courses were useful and "cost effective".

\section{COMMITTEES}

No less than seven committees sponsored by government* and two sponsored by professional bodies $\dagger$ have been convened since 1970 to deal with "laboratory safety". Several other committees-for example, those concerned with hepatitis, have also considered the problems of laboratory-acquired infections.

It would be interesting to speculate on how much these committees, especially the former group, have cost the NHS in time, travelling, subsistence, accommodation, secretarial assistance, etc. And then to reflect that all, or nearly all of the information, guidance and advice issued had already been published and for many years was readily available to all who wished to study it.

\section{Conclusions}

It is alleged that the price of safety in pathology laboratories is too high. No complaints have been made, however, about the price of safety in other NHS areas, such as fire prevention, radiation protection, electrical appliances, lifts, and pressure vessels. The NHS has an enviable reputation for safety in these fields, but no-one has suggested that because casualties have been few or none the regulations and safety precautions should be relaxed. This would

\footnotetext{
*Central Pathology Committee; Laboratory Use of Dangerous Pathogens Working Party; Dangerous Pathogens Advisory Group; Genetic Manipulation Advisory Group; Working Party to Formulate a Code of Practice for the Prevention of Infection in Clinical Laboratories; the Interim Advisory Committee; and the Advisory Committee on Dangerous Pathogens. †The Microbiological Consultative Committee; and the Joint Working Party on the Prevention of Infection in Clinical Laboratories.
} 
undoubtedly save a great deal of money. Yet because evidence of laboratory-acquired infections has been ignored or dismissed as anecdotal it is proposed that precautions need not be taken to protect laboratory workers. Much has been made of the jargon phrase "cost-effectiveness". One wonders why this is applied only to laboratory safety.

The basis of microbiological safety is Good Laboratory Practice (GLP) just as in industry accidents are prevented by Good Manufacturing Practice (GMP). But GLP and GMP require more than just good technique. They require suitable premises, correct equipment, and good training.

We suggest, therefore, that the "cost of Howie" or the "price of safety" is too often inflated by the result of earlier failure to provide the basic ingredients now enjoyed by the rest of the population under the SHW Act. We end with a passage from a recent book $^{6}$ which considers, among other things, the costs of microbiological safety.

"If microbiological safety means preventing laboratory-acquired infections by replacing inherently unsafe techniques by those proved to be safer, providing sound instead of suboptimal equipment and well-planned instead of ill-designed premises, then certainly microbiological safety is not a waste of time and resources. Diseases cost money, but good techniques cost no more than bad ones; good equipment and premises cost no more, and in the long run much less than bad ones."

\section{References}

' DHSS. Code of practice for the prevention of infection in clinical laboratories. London: HMSO, 1978.

2 HSE. Consultative Document. Dangerous pathogens. London: Health and Safety Executive, 1979.

${ }^{3}$ Howie JW, Collins CH. The Howie Code for preventing infection in clinical laboratories. Comment on some general criticisms and specific complaints. Br Med J 1980;ii:1071-4.

4 Cohen DR. The Howie Code: is the price of safety too high? J Clin Pathol 1982;35:1018-23.

${ }^{5}$ Committee of Public Accounts. 17th Report Session, 1981-82. London: HMSO, 1982.

- Collins CH. Laboratory-acquired infections. London: Butterworths, 1983.

' Report to the Public Health Laboratory Service and the Central Pathology Committee of a special working party. Precautions against tuberculous infection in the diagnostic laboratory. Mon Bull Min Hlth PHLS 1958;17:10-8.

${ }^{8}$ DHSS. Precautions against tuberculous infection in the diagnostic laboratory. HM(70)60. London: NHS, 1980.

${ }^{9}$ DHSS. Safety in pathology laboratories. London: HMSO, 1972.

${ }^{10}$ Collins $\mathrm{CH}$, Hartley EG, Pilsworth $\mathrm{R}$. The prevention of laboratory-acquired infections. Public Health Laboratory Service Monograph No 6. London: HMSO, 1974.

"Collins CH. Instruction in laboratory safety. Med Lab World 1980;4:14-9.

Requests for reprints to: $\mathrm{Mr} \mathrm{CH}$ Collins, The Ashes, Hadlow, Kent TN11 0AS, England. 